\title{
Analytical study of adult attention deficit hyperactivity disorder symptoms and internet addiction among medical students
}

\author{
Dhiraj D. Kandre ${ }^{1}$, Ankita Vikrambhai Patel², Prakash I. Mehta ${ }^{3}$ \\ 'Department of Psychiatry, GMERS Medical College and Hospital, Himmatnagar, Gujarat, India \\ ${ }^{2}$ Department of Psychiatry, GMERS Medical College and Hospital, Vadnagar, Gujarat, India \\ ${ }^{3}$ Department of Psychiatry, GMERS Medical College and Hospital, Sola, Ahmedabad, Gujarat, India \\ Neuropsychiatria i Neuropsychologia 2020; 15, 1-2: 7-12
}

Address for correspondence:

Ankita Vikrambhai Patel

Department of Psychiatry

GMERS Medical College and Hospital

Vadnagar, Gujarat, India

e-mail: avevenstar@gmail.com

\section{Abstract}

Introduction: Adult attention deficit hyperactivity disorder (ADHD) has a prevalence of $4.4 \%$ worldwide. Adults with ADHD are more prone to risk taking behaviours, behavioural addictions and substance abuse. Studies have shown that adults with ADHD are more likely to develop internet addiction (IA).

Aim of the study: To determine scoring of medical students on an adult ADHD scale and internet addiction scale and to compare it. To compare the scoring in context to demographic characteristics and substance use.

Material and methods: Medical students from two medical colleges from Gujarat participated in the study. Students filled in a semi-structured proforma which included sociodemographic details and details regarding internet use. Students completed self-report scales such as the Adult ADHD Self Report Scale (ASRS) and Young Internet Addiction Scale (IAS). Descriptive analysis was done using SPSS 20.0.

Results: Out of 427 subjects, $233(54.6 \%)$ were male and $194(45.4 \%)$ were female. On IAS, $359(84.15 \%)$ were found to be average online users (no addiction), 64 (15\%) had frequent problems with internet use (possibly addicted) and only $4(0.9 \%)$ students had excessive internet use (severely addicted). In screening for adult ADHD, $84(19.7 \%)$ were found to be positive. Adult ADHD was found to be significantly associated with IA and substance use.

Discussion: Deficiency in inhibitory control, reward deficiency syndrome and cognitive and motivational dysfunction have been observed in ADHD, which makes subjects with ADHD at risk of developing IA and substance use.

Conclusions: Being positive on the Adult ADHD Scale was found to be significantly associated with IA and substance use.

Key words: adult attention deficit hyperactivity disorder, internet addiction, medical students.

\section{Introduction}

Attention deficit hyperactivity disorder (ADHD) is a neurodevelopmental and behavioural disorder affecting preschoolers, children, adolescents and adults around the world, characterized by diminished sustained attention and increased impulsivity or hyperactivity. ADHD affects $5 \%$ to $8 \%$ of school aged children. $60 \%$ to $85 \%$ who meet criteria of ADHD in childhood continue to show symptoms of ADHD in adolescence and adulthood (Kaplan \& Sadock's synopsis of psychiatry, $11^{\text {th }}$ edition). Prevalence of adult ADHD is $4.4 \%$ (Kessler et al. 2016).
If these difficulties are not managed appropriately, they can cause associated behavioural, emotional, social, vocational and academic problems. Adults with ADHD typically have difficulty following directions, remembering information, concentrating, or completing work within time limits or meeting appointments. Such adults are more prone to risk taking behaviours, behavioural addictions and substance abuse (APA, DSM-5 2013; Neuman et al. 2005; Wolraich et al. 1998; Biederman et al. 2000).

In the current time and age, the internet has come to occupy an irremovable place in our daily life. The internet is used extensively by 
youth and adolescents for entertainment, education, social networking and information sharing (Kuss and Griffiths 2011). Internet addiction (IA) is defined by Young as an individual's inability to control his or her use of the internet, which eventually causes marked distress and/ or functional impairment (Young et al. 1996; Young et al. 1998; O'Reilly 1996; Young and Rodgers 1998). Internet addiction is also called pathological internet use, problematic internet use, excessive internet use, internet dependence, compulsive computer use or virtual addiction (Bozkurt et al. 2013). Classification of internet addiction is controversial as it was classified as an impulse control disorder or excessive compulsive disorder or behaviour addiction (Shapira et al. 2000). In DSM-5 internet gambling disorder has been kept in the appendix for future research. Internet addiction is associated with many psychiatric co-morbidities such as ADHD, mood disorder and anxiety disorder (Bozkurt et al. 2013; Shapira et al. 2000; Black et al. 1999).

Aside from the benefits, internet use also results in some negative impacts, such as internet addiction. The prevalence of internet addiction ranges from $1 \%$ to $36.7 \%$ in a literature review (Ko et al. 2012). A study by Morahan-Martin and Schumacher (2000) demonstrated that $8 \%$ to $13 \%$ of undergraduates are addicted to the internet, which has impaired individual psychological wellbeing, peer and family interactions, and academic performance.

A study by Ko et al. (2008) demonstrated that college students with internet addiction are more likely to have adult ADHD. Rapid response and multiple windows with different activities might prevent feelings of boredom in the ADHD population. Persistent predictable rewards also contribute to their vulnerability to form the habit of internet use (Ko et al. 2008; Castellanos and Tannock 2002; Diamond 2005). On the other hand, since there is a deficit of response to punishment, adult ADHD sufferers would pay little attention to the negative consequences of heavy internet use (Berger and Cassuto 2014). The shortage of self-control and impairment of inhibitions in performance may place college students at higher risk of development of internet addiction (Yen et al. 2017).

In the Indian context, a study from south India by Piplani et al. (2019) found ADHD and IA significantly associated in young adults. In the study, out of 618 students, $19.48 \%$ had moderate IA and $61.16 \%$ had mild IA and $7.28 \%$ were suspected positive for adult ADHD. In a study from north India by Enagandula et al. (2018), similar results were seen as IA was found to be more common in children and adolescents who had ADHD. In a study by Bozkurt et al. (2013), in adolescents referred with internet addiction for psychiatry evaluation, ADHD (83.3\%) was the most common diagnosis followed by anxiety disorder $(71.7 \%)$ and mood disorder (38.3\%).

From India, there are several studies of IA in medical students which show significant number of medical students having IA and it has adverse consequences for their physical and mental health (Gedam et al. 2017; Cynthia and Kalyani 2017; Patil et al. 2017). In a study by Gedam et al. (2017), from the Maharashtra region, out of 846 medical students $19.85 \%$ were found to have IA. In a recent study from south India, by Athulya et al. (2019), out of 381 medical students' prevalence of IA was as high as $61 \%$.

Adult ADHD and its association with psychological disturbances have been found by many studies, but as IA is a newer condition, research showing an association between these two conditions is scarce. IA is more prevalent among college students according to recent studies. College students with internet addiction are more likely to have adult ADHD. Screening for these both conditions and their association with one another can help in understanding their bidirectional relationship and developing preventive measures for the same. Exploration of both conditions will assist in preventive and therapeutic measures. The scarcity of studies about the subject, more so in Gujarat, prompted us to conduct the study.

Aims and objectives: To determine scoring of medical students on an adult ADHD scale and internet addiction scale and to compare it. To compare the scoring in context to demographic characteristics and substance use.

\section{Material and methods}

For this cross sectional study, two medical colleges in Gujarat were approached. After taking permission from the concerned authority and Institutional Ethical Committee, medical undergraduate, postgraduate and intern students were approached for the study. Permission from concerned faculty was taken for providing time to students to fill in the proforma. Students were explained about the nature of the study and anonymity of it. Students who were above 18 years of age and willing to give consent for the study were included in the study. They were given a semi-structured proforma which 
covered details about socio-demographic data and internet usage which covered details about the total internet usage (hours) per week, years of internet use, main purpose of internet use, type of internet media, type of behavioural addictions, etc. Students completed self-report scales such as the Adult ADHD Self Report Scale (ASRS) and Young Internet Addiction Scale (IAS).

Young's Internet Addiction Scale (Young et al. 1996): Young's Internet Addiction Scale (IAS) is a self-report questionnaire comprising 20 questions with a 5-point Likert scale in which 1 - rarely and 5-always. IAS is a scale widely used to measure internet addiction. In this study, we assessed the severity of internet problems based on the original cut-off points proposed by Young. The total score ranges from 20 to 100 in which a higher score reflects a tendency towards IA. An IAS score of 20-39 represents average internet use (no addiction), a score of 40-69 represents over-use of the internet which causes frequent problems (possible addiction) and a score of 70-100 represents excessive internet use which causes significant problems (severe addiction).

Adult ADHD Self Report Scale (ASRS-v1.1) (Kessler et al. 2007): The ASRS was developed in conjunction with the World Health Organization and a workgroup on adult ADHD. The ASRS-V1.1 Symptom Checklist has two parts: Part A (six items) and Part B (12 items). These 18 items correlate closely with diagnostic criteria of ADHD in DSM-IV-TR. The ASRS asks respondents about the past 6 months and uses a 5-point response scale (never, rarely, sometimes, often, and very often). The ASRS V-1.1 Part $A$ is recommended as a screening tool for adult ADHD (Piplani et al. 2019). If four or more marks appear on darkly shaded boxes of part A then the person has symptoms highly consistent with adult ADHD (screening positive), which warrants further assessment. Descriptive analysis was done using SPSS 20.0. Categorical data were presented as number and percentage. To compare categorical variables the chi-square test was used and a $p$-value $<0.05$ was taken to be significant.

\section{Results}

A total of 500 medical undergraduate students participated in the study, out of which 427 subjects (response rate $85.4 \%$ ) were kept in the study as the other students did not give consent and or had an incompletely filled in proforma.
Out of 427 subjects, $233(54.6 \%)$ were male and 194 (45.4\%) were female. On the IAS, $359(84.15 \%)$ were found to be average online users (no addiction), 64 (15\%) had a frequent problem with internet use (possibly addicted) and only $4(0.9 \%)$ students had excessive internet use (severely addicted). In screening for adult ADHD, 84 (19.7\%) were found to be positive. Most of the subjects reported use of the internet for social networking (82\%) and to search for information (60.65\%). $17.09 \%$ and $11.94 \%$ of subjects also used the internet for online gaming and pornography respectively. More than $71 \%$ of subjects reported use of a gadget for more than 12 months with $7.7 \%$ using the internet more than 40 hours per week. IA was significantly associated with adult ADHD and younger age group. ADHD was significantly associated with substance use (Tables 1-5).

\section{Discussion}

In our study, out of 427 subjects, $15.9 \%$ were found to have possible/severe IA and $19.7 \%$ were positive for adult ADHD on ASRS. 35.71\% of subjects from the adult ADHD positive group had a higher internet addiction score. $44.12 \%$ of subjects from the IA group (possible or severe addiction) scored positively for adult ADHD on ASRS. ADHD and internet addiction were

Table 1. Demographical details and categorical variable of all students included in study

\begin{tabular}{|c|c|}
\hline Variables & $\begin{array}{c}n(\%) \\
N=427\end{array}$ \\
\hline \multicolumn{2}{|l|}{ Age (years) } \\
\hline $18-20$ & $344(80.6)$ \\
\hline $21-23$ & $61(14.3)$ \\
\hline $24-26$ & $22(5.2)$ \\
\hline \multicolumn{2}{|l|}{ Gender } \\
\hline Male & $233(54.6)$ \\
\hline Female & $194(45.4)$ \\
\hline \multicolumn{2}{|l|}{ Internet addiction } \\
\hline No addiction & $359(84.1)$ \\
\hline Possible addiction & $64(15.0)$ \\
\hline Severe addiction & $4(0.9)$ \\
\hline \multicolumn{2}{|l|}{ ASRS } \\
\hline Negative & $343(80.3)$ \\
\hline Positive & $84(19.7)$ \\
\hline
\end{tabular}

ASRS - Adult ADHD Self Report Scale 
found to be significantly associated. This finding may suggest that ADHD is an important risk factor for internet addiction.

Table 2. Pattern of internet use among participants

\begin{tabular}{lc} 
Variables & $n(\%)$ \\
\hline \begin{tabular}{l} 
Type of internet usage \\
\hline Message/texts/e-mail
\end{tabular} & $178(41.69)$ \\
\hline Social networking & $350(81.96)$ \\
\hline Information search & $259(60.65)$ \\
\hline Online gaming & $73(17.09)$ \\
\hline Sexual content & $51(11.94)$ \\
\hline Duration since usage of gadget & $120(28.1)$ \\
\hline$<12$ months & $307(71.9)$ \\
\hline$\geq 12$ months & $394(92.3)$ \\
\hline Time spent online per week & $33(7.7)$ \\
\hline$<40$ hours & \\
\hline$\geq 40$ hours
\end{tabular}

In our study, prevalence IA was found to be $15.9 \%$. A similar result was seen in a study by Gedam et al. (2017) and Raju Srijampana et al. (2014) in which $19.85 \%$ and $12.2 \%$ of medical students had IA. In a study by Patil et al. (2017), 34.83\% and 3.68\% of medical students had possible IA and severe IA respectively with IA being more common in males than females. Risk of IA being higher in males than females can be explained by the fact that males tend to seek contact online and female have more supervision or restriction of internet use in the family. No significant difference was found between male and female subjects regarding internet use in our study. In our study internet addiction was significantly associated with young age. As per a meta-analytic study by Wang et al. (2017), males and young adults are more likely to be diagnosed with internet addiction.

In the ADHD group $35.71 \%$ and in the non-ADHD group $11.07 \%$ of subjects were found to have internet addiction on the IAS. Similar results were seen in a study by Yoo et al.

Table 3. Correlation between internet addiction and positive score on adult ADHD

\begin{tabular}{lcccc} 
Internet addiction & \multicolumn{2}{c}{ ASRS screening } & Total & \\
\cline { 2 - 3 } No addiction & negative & positive & & \\
Possible addiction & 305 & 54 & $649(84.1 \%)$ & $\begin{array}{c}\chi^{2}=38.98 \\
p<0.0001\end{array}$ \\
\hline Severe addiction & 38 & 26 & $4(0.9 \%)$ \\
\hline Total & 0 & 4 & 427 \\
\hline
\end{tabular}

ASRS - Adult ADHD Self Report Scale

Table 4. Correlation between positive score on adult ADHD and substance use

\begin{tabular}{|c|c|c|c|c|c|}
\hline \multirow[t]{2}{*}{ ASRS screening } & \multicolumn{3}{|c|}{ Substance use } & \multirow[t]{2}{*}{ Total } & \\
\hline & absence & often & regular & & \\
\hline Negative & 338 & 2 & 3 & $343(80.3 \%)$ & \multirow{3}{*}{$\begin{array}{l}\chi^{2}=5.96 \\
p=0.05\end{array}$} \\
\hline Positive & 79 & 2 & 3 & 84 (19.7\%) & \\
\hline Total & 417 (97.7\%) & $4(0.9 \%)$ & $6(1.4 \%)$ & 427 & \\
\hline
\end{tabular}

ASRS - Adult ADHD Self Report Scale

Table 5. Correlation between internet addiction and age

\begin{tabular}{|c|c|c|c|c|c|}
\hline \multirow[t]{2}{*}{ IA score } & \multicolumn{3}{|c|}{ Age (years) } & \multirow[t]{2}{*}{ Total } & \\
\hline & $18-20$ & $21-23$ & $24-26$ & & \\
\hline No addiction & 287 & 57 & 15 & 359 (84.1\%) & \multirow{4}{*}{$\begin{array}{l}\chi^{2}=9.37 \\
p=0.05\end{array}$} \\
\hline Possible addiction & 53 & 4 & 7 & $64(15.0 \%)$ & \\
\hline Severe addiction & 4 & 0 & 0 & $4(0.9 \%)$ & \\
\hline Total & 344 (80.6\%) & 61 (14.3\%) & 22 (5.2\%) & 427 & \\
\hline
\end{tabular}

A - internet addiction 
(2014), in which $32.7 \%$ of ADHD group and $3.2 \%$ of non-ADHD group subjects met criteria for internet addiction on the IAS. In a study by Bozkurt et al. (2013), 83.3\% of young adolescents with IA showed symptoms of ADHD. In a study by Tateno et al. (2016), a strong relationship was found between ADHD traits and IA in Japanese students. A meta-analysis by Wang et al. (2017) showed a similar moderate association between IA and ADHD in adolescents and young adults even after controlling for confounding factors.

The association between ADHD and IA can be explained by several hypotheses. The stopsignal paradigm is based on the formal theory of inhibition and measures the mechanism of inhibition. Subjects with ADHD have shown a deficiency in inhibitory control which is developed by grade 2 in normal subjects. This deficiency in inhibition control in ADHD may interfere with self-regulation with internet use (Schachar and Logan 1990).

The dopaminergic and opioidergic reward pathways of the brain are critical for survival since they provide the pleasure drives for eating, love and reproduction. These are called 'natural rewards' and involve the release of dopamine in the nucleus accumbens and frontal lobes. However, the same release of dopamine and production of sensations of pleasure can be produced by 'unnatural rewards'. Defects in various combinations of the genes for neurotransmitters and defects in functioning of the frontal lobe result in a reward deficiency syndrome (RDS) which places individual at risk for abuse of the unnatural rewards. Internet addiction can also serve as an 'unnatural reward'. In ADHD and other impulsive disorders a similar reward deficiency syndrome is seen. The reward deficiency hypothesis can serve as a major tool in understanding the link between ADHD and internet addiction (Comings and Blum 2000; Blum et al. 1996).

Sonuga-Barke's hypothesis suggests the dual pathway model for ADHD. In one pathway, dysregulation of action results from poor inhibitory control associated with the mesocortical branch of the dopaminergic system. In the other pathway it is a motivational style characterized by an altered delay of reward gradient linked to the meso-limbic dopamine branch associated with the reward circuits. Cognitive and motivational dysfunction in ADHD causes the individual to choose tasks which are immediately rewarding rather than delayed ones. The internet provides an individual with multimodal stimuli with an instant reward which makes an individual with
ADHD susceptible to abuse of the internet (Sonuga-Barke 2002).

In our study substance use was found to be significantly associated with ADHD. The reward deficiency hypothesis, poor inhibitory control and motivation dysfunction can explain why subjects with ADHD are more prone to substance abuse. Some studies have also suggested conduct disorder as a mediator for substance related disorder in ADHD (Tapert et al. 2002; Biederman et al. 1998; Disney et al. 1999; Chilcoat and Breslau 1999).

\section{Limitations}

Diagnosis of internet addiction needs to be refined with standardized diagnostic tools to improve reliability and validity. It is a cross sectional study. The long term effect of ADHD on internet addiction cannot be studied by this method. A screening test of ADHD was used. No clinical interview of subjects who were positive in ADHD screening was carried out.

\section{Conclusions}

The findings of this study suggest there is a strong association between scoring for adult ADHD and internet addiction. Individuals with ADHD are more prone to develop substance and or behaviour addiction. In future, a much clearer definition of internet addiction should be developed and a diagnostic entity needs to be provided. Screening for ADHD should be done in college students as ADHD can affect an individual's academic performance, interpersonal relationships and make one more prone to substance use and/or addiction.

\section{Disclosure}

The authors declare no conflict of interest.

\section{References}

1. American Psychiatric Association. Diagnostic and Statistical Manual of the American Psychiatric Association 5. American Psychiatric Association, Washington, DC 2013.

2. Athulya AG, Varghese VA, Raajev A. (2019) Internet addiction among medical students and its impact on academic performance: an Indian study. JMSCR 2019; 7: 670-677.

3. Berger I, Cassuto $H$. The effect of environmental dis-tractors incorporation into a CPT on sustained attention and ADHD diagnosis among adolescents. J Neurosci Methods 2014; 222: 62-68.

4. Biederman J, Wilens TE, Mick E et al. Does attentiondeficit hyperactivity disorder impact the developmental course of drug and alcohol abuse and dependence? Biol Psychiatry 1998; 44: 269-273. 
5. Biederman J, Mick E, Faraone SV et al. Age-dependent decline of symptoms of attention deficit hyperactivity disorder: impact or remission definition and symptoms type. Am Psychiatry 2000; 157: 816-818.

6. Black DW, Belsare G, Schlosser S. Clinical features, psychiatric comorbidity, and health-related quality of life in persons reporting compulsive computer use behavior. J Clin Psychiatry 1999; 60: 839-844.

7. Blum K, Cull J, Braverman E, et al. Reward deficiency syndrome. Am Scientist 1996; 84: 132-145.

8. Bozkurt $\mathrm{H}$, Coskun M, Ayaydin $\mathrm{H}$, et al. Prevalence and patterns of psychiatric disorders in referred adolescents with Internet addiction. Psychiatry Clin Neurosci 2013; 67: 352-359.

9. Castellanos FX, Tannock R. Neuroscience of attention-deficit/hyperactivity disorder: the search for endophenotypes. Nat Rev Neurosci 2002; 3: 617-628.

10. Chilcoat HD, Breslau N. Pathways from ADHD to early drug use. J Am Acad Child Adolesc Psychiatry 1999; 38: 1347-1354.

11. Comings DE, Blum K. Reward deficiency syndrome: genetic aspects of behavioral disorders. Prog Brain Res 2000; 126: 325-341.

12. Cynthia SS, Kalyani P. A cross-sectional study on internet addiction among medical students. Int J Commun Med Public Health 2017; 4: 670-674.

13. Diamond A. Attention-deficit disorder (attention-deficit hyperactivity disorder without hyperactivity): a neurobiologically and behaviorally distinct disorder from attention-deficit/hyperactivity disorder (with hyperactivity). Dev Psychopathol 2005; 17: 807-825.

14. Disney ER, Elkins IJ, McGue M, et al. Effects of ADHD, conduct disorder, and gender on substance use and abuse in adolescence. Am J Psychiatry 1999; 156: 1515-1521.

15. Enagandula R, Singh S, Adgaonkar GW, et al. Study of internet addiction in children with attention-deficit hyperactivity disorder and normal control. Ind Psychiatry 2018; 27: 110-114.

16. Gedam SR, Ghosh S, Modi L, et al. Study of internet addiction: prevalence, pattern and psychopathology among health professional undergraduates. Indian J Soc Psychiatry 2017; 33: 305-311.

17. Kaplan \& Sadock's synopsis of psychiatry: Behavioral sciences/clinical psychiatry. $11^{\text {th }}$ ed. Wolters Kluwer, Philadelphia 2014; 1066-1069.

18. Kessler RC, Adler LA, Gruber MJ, et al. Validity of the World Health Organization Adult ADHD Self-Report Scale (ASRS) Screener in a representative sample of health plan members. Int J Methods Psychiatr Res 2007; 16: 52-65.

19. Kessler RC, Adler L, Barkley R, et al. The prevalence and correlates of adult ADHD in the United States: results from the National Comorbidity Survey Replication. Am J Psychiatry 2016; 163: 716-723.

20. Ko CH, Yen JY, Chen CS, et al. Psychiatric comorbidity of internet addiction in college students: An interview study. CNS Spectr 2008; 13: 147-153.

21. Ko CH, Yen JY, Yen CF, et al. The association between internet addiction and psychiatric disorder: a review of the literature. Eur Psychiatry 2012; 27: 1-8.

22. Kuss DJ, Griffiths MD. Online social networking and addiction - a review of the psychological literature. Int J Environ Res Public Health 2011; 8: 3528-3552.

23. Morahan-Martin JM, Schumacher P. Incidence and correlates of pathological internet use among college students. Comput Human Behav 2000; 16: 13-29.

24. Neuman RJ, Sitdhiraksa N, Reich W, et al. Estimation of prevalence of DSM-IV and latent class-defined ADHD subtypes in a population-based sample of child and adolescent twins. Twin Res Hum Genet 2005; 8: 392-401.

25. O'Reilly $M$. Internet addiction: a new disorder enters the medical lexicon. CMAJ 1996; 154: 1882-1883.

26. Patil S, Deshmukh JS, Dagdiya KR, et al. Prevalence and pattern of internet addiction among medical students in Nagpur, Maharashtra. Int J Commun Med Public Health 2017; 4: 2412-2416.

27. Piplani S, Bhushan S, Tekkalaki BV, et al. Internet addiction and ADHD, are they significantly related? Int J Community Med Public Health 2019; 6: 615-618.

28. Raju Srijampana VG, Endreddy AR, Prabhath K, et al. Prevalence and patterns of internet addiction among medical students. Med J DY Patil Univ 2014; 7: 709-713.

29. Schachar R, Logan GD. Impulsivity and inhibitory control in normal development and childhood psychopathology. Dev Psychol 1990; 26: 710-720.

30. Shapira N, Goldsmith TD, Keck Jr PE, et al. Psychiatric features of problematic Internet use. J Affect Disord 2000; 57: 267-272

31. Sonuga-Barke EJ. Psychological heterogeneity in ADHD A dual pathway model of behaviour and cognition. Behav Brain Res 2002; 130: 29-36.

32. Tapert SF, Baratta MV, Abrantes AM, et al. Attention dysfunction predicts substance involvement in community youth. J Am Acad Child Adolesc Psychiatry 2002; 41: 680-686.

33. Tateno M, Teo AR, Shirasaka T, et al. Internet addiction and self-evaluated attention-deficit hyperactivity disorder traits among Japanese college students. Psychiatry Clin Neurosci 2016; 70: 567-572.

34. Wang B, Yao NO, Zhou X, et al. The association between attention deficit/hyperactivity disorder and internet addiction: a systematic review and meta-analysis. BMC Psychiatry 2017; 17: 260.

35. Wolraich ML, Hannah JN, Baumgaertel A, et al. Examination of DSM-IV criteria for attention deficit/hyperactivity disorder in a county-wide sample. J Dev Behav Pediatr 1998; 19: 162-168.

36. Yen JY, Liu TL, Wang PW, et al. Association between internet gaming disorder and adult attention deficit hyperactive disorder and their correlates: Impulsivity and hostility. Addict Behav 2017; 64: 308-313.

37. Yoo HJ, Cho SC, Ha J, et al. Attention deficit hyperactivity symptoms and Internet addiction. Psychiatry Clin Neurosci 2014; 58: 487-494.

38. Young KS. Psychology of computer use: XL. Addictive use of the Internet: a case that breaks the stereotype. Psychol Report 1996; 79: 899-902.

39. Young KS, Rodgers RC. The relationship between depression and internet addiction. Cyberpsychol Behav 1998; 1 25-28.

40. Young KS. Caught in the net: how to recognize the signs of internet addiction - and a winning strategy for recovery. Wiley, New York 1998. 